\title{
Production of chitooligosaccharides from Rhizopus oligosporus NRRL2710 cells by chitosanase digestion
}

\author{
Maria Mahata $^{\mathrm{b}, \dagger}$, Shoko Shinya ${ }^{\mathrm{a} \dagger}$, Eiko Masaki ${ }^{\mathrm{a}}$, Takashi Yamamoto ${ }^{\mathrm{a}}$, Takayuki Ohnuma ${ }^{\mathrm{a}}$, \\ Ryszard Brzezinski $^{c}$, Tapan K. Mazumder ${ }^{\mathrm{d}}$, Kazuhiko Yamashita ${ }^{\mathrm{d}}$, Kazue Narihiro ${ }^{\mathrm{d}}$, Tamo Fukamizo ${ }^{\mathrm{a}, *}$ \\ ${ }^{a}$ Department of Advanced Bioscience, Kinki University, 3327-204 Nakamachi, Nara 631-8505, Japan \\ ${ }^{\mathrm{b}}$ University of Andalas, Padang, West Sumatera, Indonesia \\ 'Département de Biologie, Centre d'Étude et de Valorisation de la Diversité Microbienne, Université de Sherbrooke, Canada \\ ${ }^{\mathrm{d}}$ Yaegaki Bio-industry, Inc., 681 Mukudani, Hayashida-cho, Himeji 678-4298, Japan
}

\section{A R T I C L E I N F O}

\section{Article history:}

Received 24 April 2013

Received in revised form 1 June 2013

Accepted 4 June 2013

Available online 14 June 2013

\section{Keywords:}

Rhizopus oligosporus

Fungal cell wall

Chitosanase

Partially N-acetylated chitooligosaccharides $\mathrm{CP} / \mathrm{MAS}{ }^{13} \mathrm{C}$ NMR

\begin{abstract}
A B S T R A C T
The intact cells of Rhizopus oligosporus NRRL2710, whose cell walls are abundant source of $N$-acetylglucosamine (GlcNAc) and glucosamine $(\mathrm{GlcN})$, were digested with three chitinolytic enzymes, a GH-46 chitosanase from Streptomyces sp. N174 (CsnN174), a chitinase from Pyrococcus furiosus, and a chitinase from Trichoderma viride, respectively. Solubilization of the intact cells by CsnN174 was found to be the most efficient from solid state $\mathrm{CP} / \mathrm{MAS}{ }^{13} \mathrm{C}$ NMR spectroscopy. Chitosanase products from Rhizopus cells were purified by cation exchange chromatography on CM-Sephadex C-25 and gel-filtration on Cellulofine Gcl-25 m. NMR and MALDI-TOF-MS analyses of the purified products revealed that GlcN-GlcNAc, $(\mathrm{GlcN})_{2}-\mathrm{GlcNAc}$, and $(\mathrm{GlcN})_{2}$ were produced by the enzymatic digestion of the intact cells. The chitosanase digestion of Rhizopus cells was found to be an excellent system for the conversion of fungal biomass without any environmental impact.
\end{abstract}

(c) 2013 Elsevier Ltd. All rights reserved.

\section{Introduction}

Chitin, a water-insoluble polymer of $\beta$-1,4-linked $N$-acetylglucosamine (GlcNAc), is the most abundant biomass next to cellulose, and widely distributed in organisms, such as crustacean shells, insect cuticles, and fungal cell wall. ${ }^{1}$ Commercial chitin is mainly extracted by demineralization and deproteinization of the shells of crustaceans such as shrimps, crabs, lobsters, and krill, which are supplied in large quantities by shellfish processing. ${ }^{2}$ Chitosan, a $\beta$-1,4-linked polymer of glucosamine (GlcN), has been produced on an industrial scale by the N-deacetylation of chitin using sodium hydroxide. The enzymatic hydrolysis of chitin and chitosan has been conducted to produce corresponding oligosaccharides, ${ }^{3}$ which have been drawing attention because of their presumed biological functions, such as the inhibition of tumor angiogenesis, ${ }^{4}$ control of cell growth, differentiation, and

Abbreviations: GlcNAc, 2-acetamido-2-deoxy- $\beta$-D-glucopyranose; GlcN, 2amino-2-deoxy- $\beta$-D-glucopyranose; $(\mathrm{GlcN})_{n}, \beta$-1,4-linked oligosaccharide of GlcN with a polymerization degree of $n$; MALDI-TOF-MS, matrix assisted laser desorption/ionization time-of-flight mass spectrometry; NMR, nuclear magnetic resonance.

* Corresponding author. Tel.: +81 74243 8237; fax: +81 742438976.

E-mail address: fukamizo@nara.kindai.ac.jp (T. Fukamizo).

These authors contributed equally to this work. development in vertebrates, ${ }^{5,6}$ antioxidative effect, ${ }^{7}$ and elicitation of defensive actions in plants. ${ }^{8,9}$ However, the extraction process of chitin from crustacean shells is well known to produce a significant impact on the environment. In this context, it is highly desirable to establish a strategy for directly producing chitin and chitosan oligosaccharides by the enzymatic digestion of raw materials containing chitin and chitosan.

Chitin is associated with proteins and minerals in crustacean shells, ${ }^{2}$ resulting in a sclerotized and recalcitrant structure, and further protecting the polysaccharide chain from enzymatic digestion. However, fungal cell wall consists of chitin, branched $\beta-1,3-$ glucan, and $\beta$-1,6-glucan, which are cross-linked to each other. Chitosan is also found in the fungal cell wall, ${ }^{10}$ and makes the cell wall structure more pliable. Therefore, the chitinous components of the fungal cell wall appear to be degradable by enzymatic actions. In fact, the digestion of the cell wall fraction of Fusarium oxysporum by chitinase and chitosanase was found to produce oligosaccharides composed of GlcNAc and GlcN. ${ }^{11,12}$ However, most studies on the chitinous components of fungal cell wall thus far have been devoted to efficient utilization of fungi as the source of polysaccharide chitin/chitosan ${ }^{13}$ or GlcN monomer. ${ }^{14,15}$ Experimental data on the oligosaccharide production from the fungal cell wall have not been fully accumulated. In order to utilize the chitooligosaccharide products obtained from the fungal cell wall as 
food additives or pharmaceutics, fungi as the source materials should be harmless; therefore, pathogenic fungi such as the Fusarium species could not be used for this purpose.

Some Rhizopus species have been used in the fermentation food industry in Asia, and their products have been generally recognized as safe. ${ }^{16}$ Thus we determined the chitin/chitosan content in several Rhizopus species, and the content in R. oligosporus was found to be the highest (32\%, Yamashita et al., unpublished). In this study, the intact cells of $R$. oligosporus were digested by chitinolytic enzymes, and the products were analyzed by NMR spectroscopy and MALDI-TOF-MS. We found that the chitosanase digestion of Rhizopus cells is an excellent strategy for chitooligosaccharide production without any impact on the environment.

\section{Results and discussion}

\subsection{Enzymatic digestibility of Rhizopus oligosporus cells}

To evaluate the enzymatic digestibility of Rhizopus cells, three enzymes were tested, an endo-splitting chitosanase from Streptomyces sp. N174 (CsnN174), a thermophilic chitinase from Pyrococcus furiosus (PfChit), and a chitinase from Trichoderma viride (TvChit). These two chitinases belong to the GH18 family and hydrolyze the internal $\beta$-1,4-glycosidic linkages (endo-splitting mode) through substrate-assisted mechanism. ${ }^{17}$ The production systems of these enzymes were highly efficient and available in our laboratory. Individual digestions of the cells were conducted for $24 \mathrm{~h}$. We confirmed that the release of reducing sugars into the supernatant fraction completely ceased after $24 \mathrm{~h}$ incubation. The amounts of the insoluble materials remaining after the enzymatic digestion were determined and compared with the starting amounts of the cells. The results are listed in Table 1. The amount of insoluble materials remaining was the lowest in the digestion with the chitosanase, CsnN174, indicating that the chitosanase has the highest digestibility (67\%). The digestibilities of the chitinase preparations (PfChit and TvChit) were comparable to each other (35-36\%), and much lower than those of CsnN174. Since the chitinase (PfChit) used in this experiment was thermophilic, the enzymatic reaction was also conducted at a higher temperature, $70^{\circ} \mathrm{C}$. However, solubilization was not enhanced by elevating the temperature. The accessibility of the enzymes to the chitin polysaccharide chain might have been restricted in the Rhizopus cell wall probably due to the ordered polysaccharide structure. When the control experiments were conducted in the absence of enzymes, reducing sugars did not significantly increase in the reaction mixture. It is evident that the cell wall polysaccharides were digested by the exogenous enzymes, but not by the endogenous ones.

\subsection{Solid-state CP/MAS ${ }^{13} \mathrm{C}$ NMR analysis of Rhizopus cells}

The insoluble materials remaining after the enzymatic digestion of Rhizopus cells were used for solid-state CP/MAS ${ }^{13} \mathrm{C}$ NMR analysis. The NMR spectra are shown in Figure 1. We initially compared the spectrum of intact Rhizopus cells (Fig. 1D) with those of authentic chitin and chitosan preparations (Fig. 1E and F) to roughly estimate the overall structure of the cell wall. Based on the previous assignment data, ${ }^{18}$ the resonances for polysaccharides were assigned as labeled in the figure. The resonances designated by asterisks and some portion of the carbonyl resonance were supposed to be derived from the protein and lipid components of Rhizopus cells. Since carbonyl and methyl carbon resonances were clearly observed, the Rhizopus cell wall was found to contain a significant portion of chitin. Line broadening of the resonances for the pyranose-ring carbons (C1-C6) indicated that a major fraction of the cell wall is a mixture of polysaccharides, such as chitin/chitosan and $\beta-1,3-$ and $\beta-1,6$-glucans. However, the shape of the C6 and C2 resonances of Rhizopus cells appeared to be similar to that of chitosan. Rhizopus cells are likely to contain chitin/chitosan abundantly in their cell walls.

When Rhizopus cells were digested by TvChit or PfChit, the resonance intensities of the methyl and carbonyl carbons were reduced by the enzymatic digestion (Fig. $1 \mathrm{~B}$ and $\mathrm{C}$ ), indicating the significant digestion of chitin polysaccharides. However, the relative intensities of $\mathrm{C} 1-\mathrm{C} 6$ in the spectra appeared to be similar to those of the intact cells. The major polysaccharide components were not markedly disrupted by the treatment with TvChit or PfChit. On the other hand, the insoluble fraction obtained after digestion of Rhizopus cells by CsnN174 exhibited lower intensities of C1-C6 (Fig. 1A). Major polysaccharide components were intensively disrupted by CsnN174. These results indicated again that solubilization of Rhizopus cells by CsnN174 was the most efficient. In the intact fungal cells, it appears that the polysaccharide structure of chitosan region is flexible, but the chitin region is rigid. This situation might have made the chitosanase enzyme more accessible to the polysaccharide chain, resulting in the more efficient degradation by CsnN174.

\subsection{Purification of the oligosaccharide products obtained by CsnN174 digestion}

The soluble fraction (1.38 g) obtained after the chitosanase digestion of Rhizopus cells was applied onto a charcoal column, and the adsorbed fraction was further employed for cation-exchange chromatography. The profile is shown in Figure 2. After the elution of a void-volume fraction, several reducing-sugar fractions were obtained, and the three major fractions I, II, and III were further purified by gel-filtration. The three purified fractions were dialyzed against distilled water, lyophilized, and employed for solution NMR spectroscopy and MALDI-TOF-MS. The recoveries of fractions I, II, and III were 21,8 , and $25 \mathrm{mg}$, respectively.

\subsection{Structure analysis of the oligosaccharide products}

Figure 3 shows the ${ }^{13} \mathrm{C}$ NMR spectra of fractions I, II, and III in solution. Two major resonances were observed in the carbonyl and methyl carbon regions of fractions I and II, and assigned to the $\alpha$ - and $\beta$-anomers of the reducing end GlcNAc residue based on their chemical shifts. In the $\mathrm{C} 1$ carbon region (90-100 ppm) of fraction $\mathrm{I}$, one resonance $\left(\mathrm{C}^{\prime}\right)$ was found at $97.8 \mathrm{ppm}$ in addition to the resonances corresponding to the $\alpha$ - and $\beta$-anomers of the reducing end GlcNAc ( $\mathrm{C} 1 \alpha$ and $\mathrm{C} 1 \beta)$, and assigned to the non-

Table 1

Amounts of the insoluble and soluble products obtained from the enzymatic digestion of Rhizopus cells

\begin{tabular}{|c|c|c|c|c|}
\hline Enzyme & Intact cells $^{*}(\mathrm{~g})$ & Insoluble products after enzymatic digestion ${ }^{*}(\mathrm{~g})$ & Soluble products $(\mathrm{g})$ & Hydrolysis \% \\
\hline CnsN174 & $2.06 \pm 0.04$ & $0.68 \pm 0.06$ & 1.38 & 67 \\
\hline PfChit & $2.10 \pm 0.05$ & $1.34 \pm 0.04$ & 0.76 & 36 \\
\hline TvChit & $2.05 \pm 0.02$ & $1.34 \pm 0.06$ & 0.71 & 35 \\
\hline
\end{tabular}

Mean values of three independent reactions with \pm SD (standard deviations). 


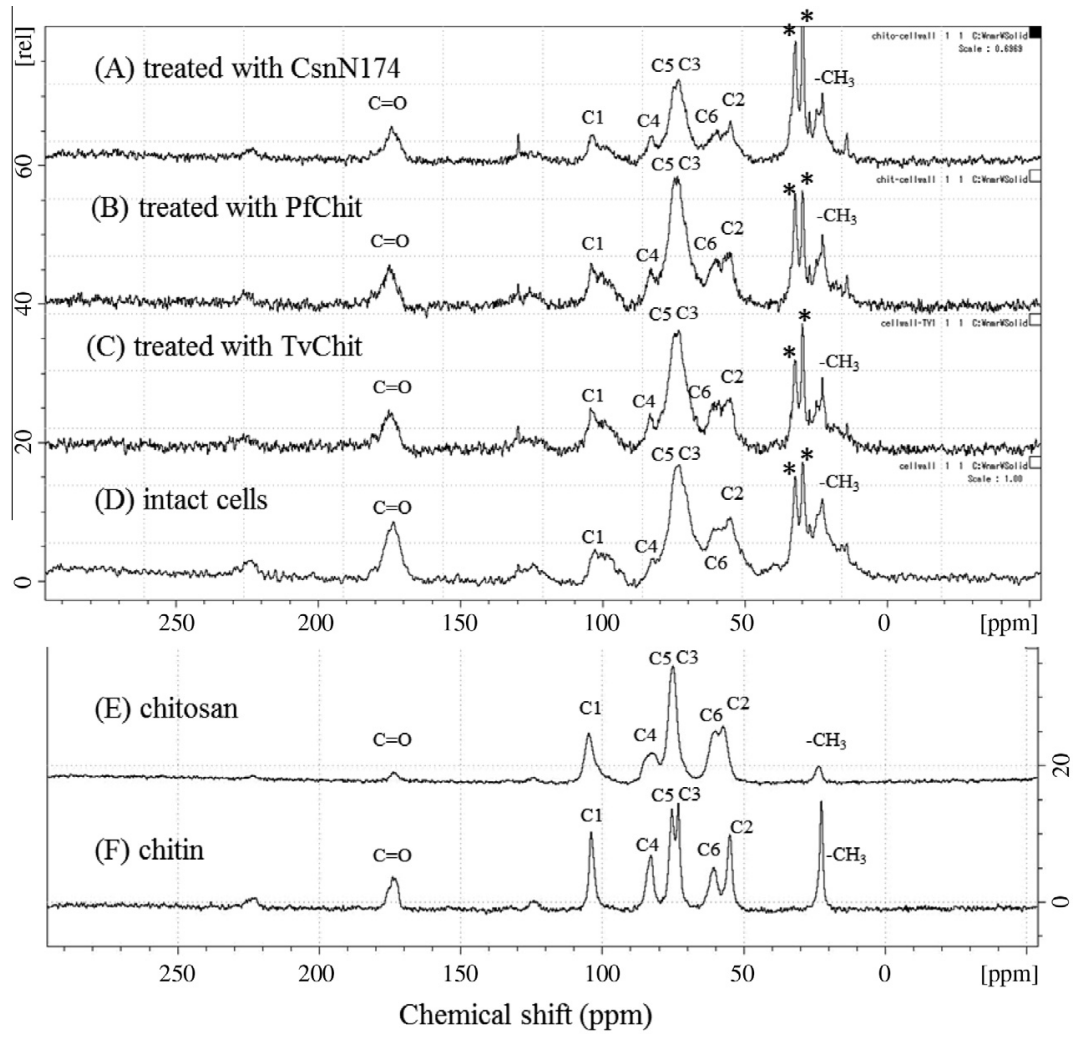

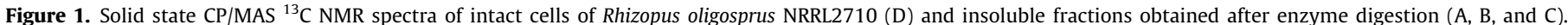

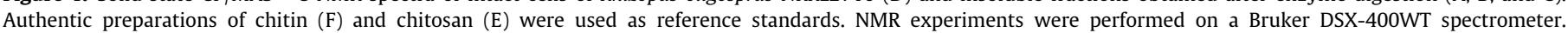
Experimental conditions are described in the text. Resonance assignments were performed based on the chemical shift values reported previously. ${ }^{14}$

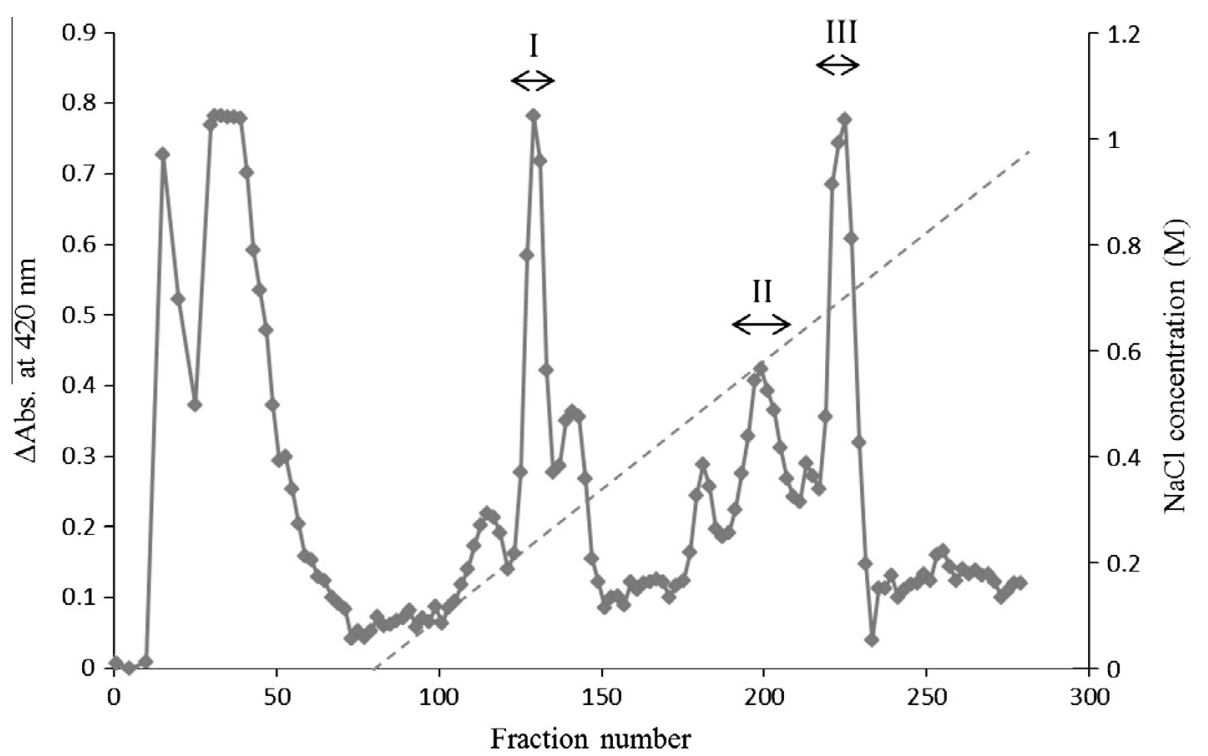

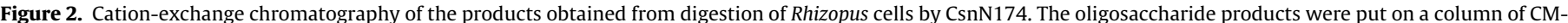

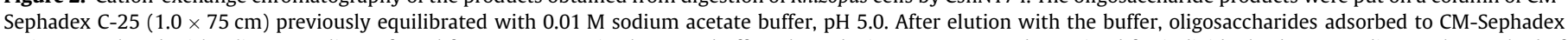

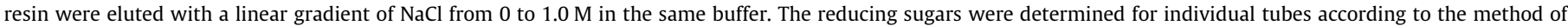
Imoto and Yagishita. ${ }^{27}$ Fractions I, II, and III were further employed for gel-filtration, and then used for structural analysis.

reducing end GlcN. Thus, fraction I was identified as GlcN-GlcNAc. The chemical shift values of the resonances for other pyranose ring carbons were consistent with the values reported for GlcN-GlcNAc. ${ }^{19}$ No resonances were observed in the carbonyl and methyl carbon regions for fraction III. Chemical shifts of the resonances for the pyranose ring carbons were completely identical to those reported for $(\mathrm{GlcN})_{2} \cdot{ }^{20,21}$ Thus, fraction III was identified as $(\mathrm{GlcN})_{2}$. Although most resonances for fraction II were identical to those observed for fraction I, six additional resonances designated by $\mathrm{C} 1^{*}-\mathrm{C} 6^{*}$ were found in the region of the pyranose-ring carbons. The chemical shifts of the six resonances corresponded to those of the internal GlcN residues. ${ }^{21}$ Although fraction II contained some 

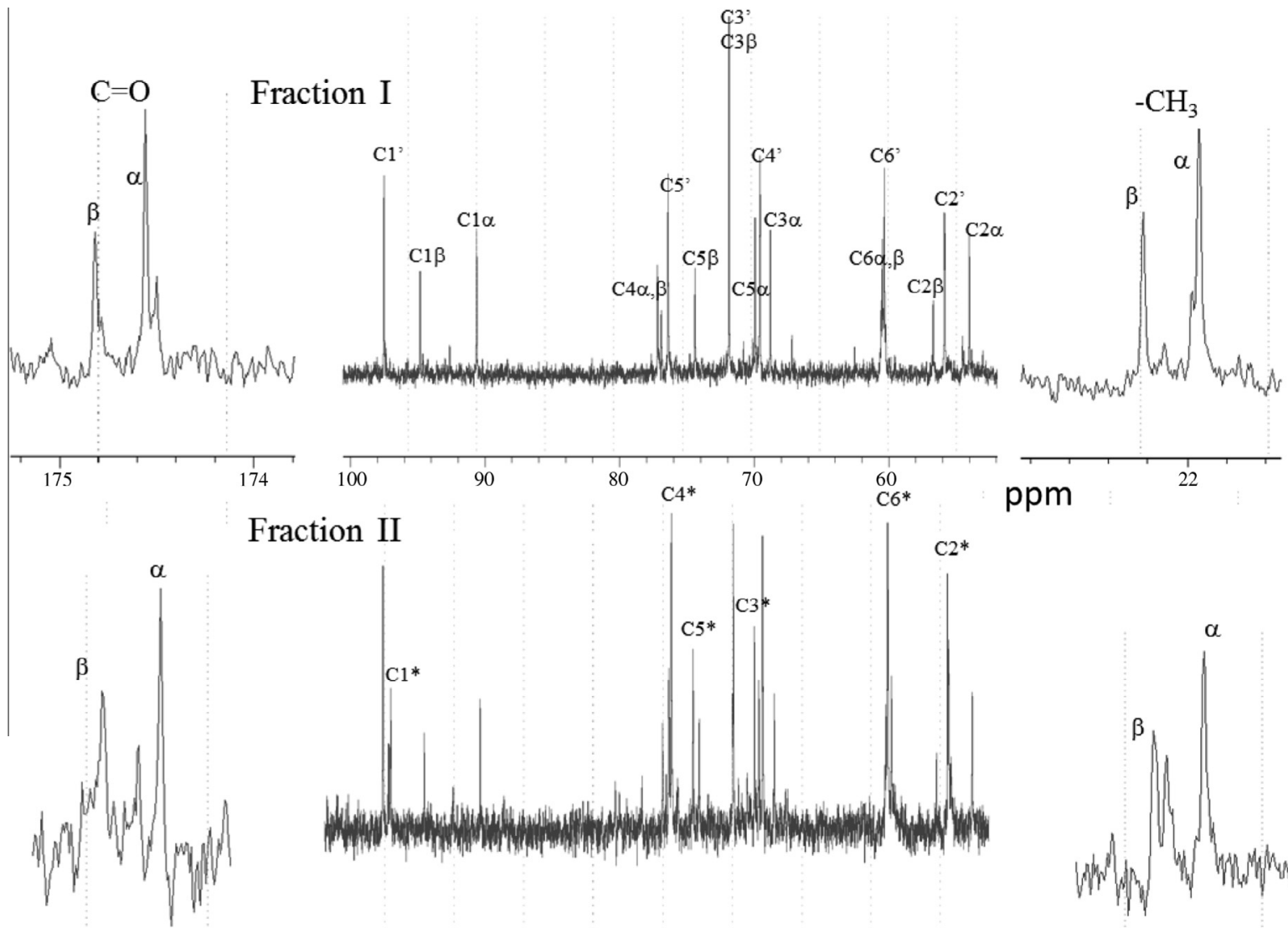

Fraction II
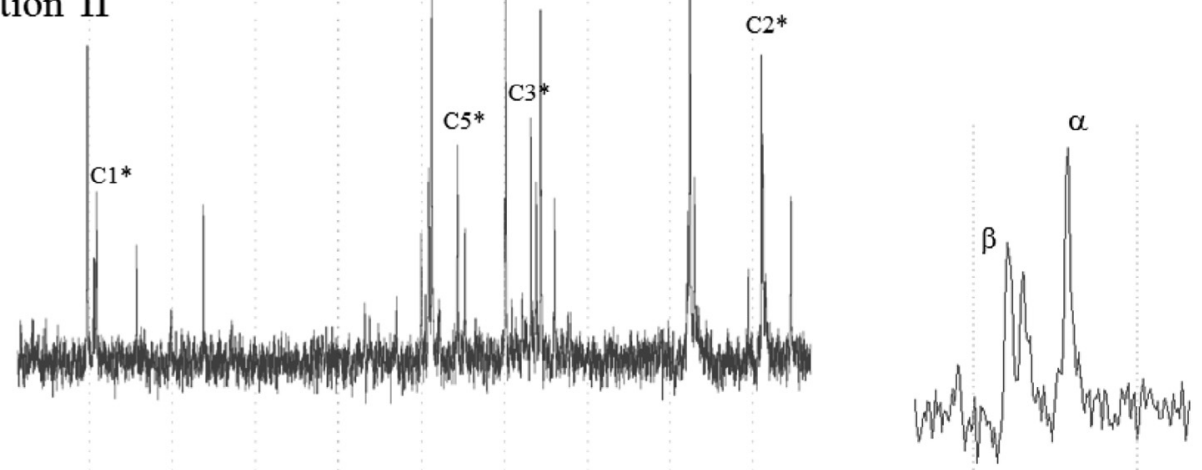

ppm
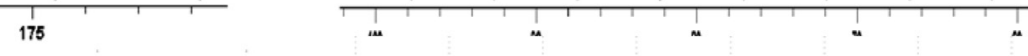

22

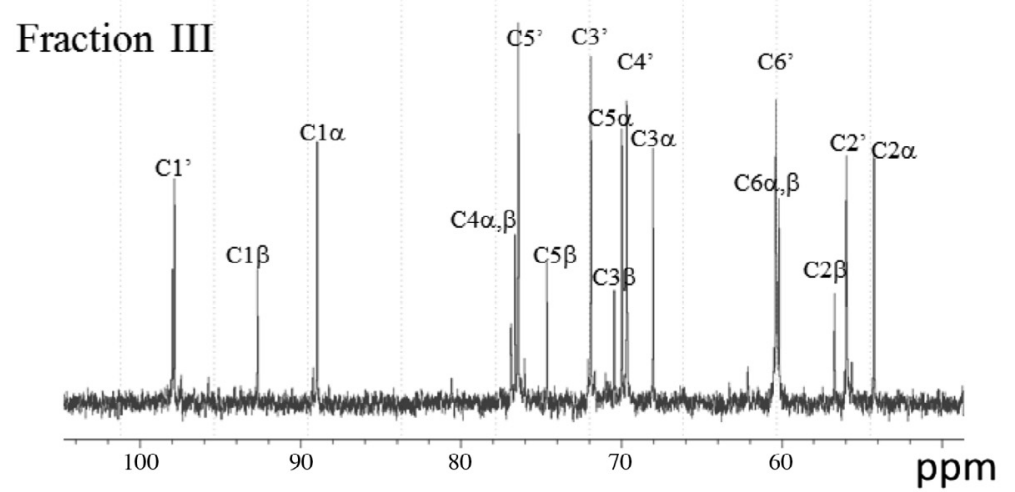

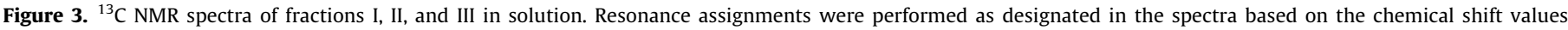

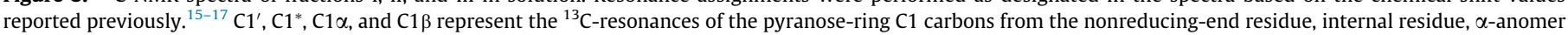
of the reducing-end residue, and $\beta$-anomer of the reducing-end residue, respectively. Similar symbols are used for the other pyranose-ring carbons (C2-C6).

impurities, a major portion of this fraction was identified as $(\mathrm{GlcN})_{2}$-GlcNAc.

Figure 4 shows the MALDI-TOF-MS profiles of the three fractions. The major mass signals of 405.2842, 566.6437, and 363.4394 for the individual fractions corresponded to the sodium adducts of the compounds GlcN-GlcNAc, $(\mathrm{GlcN})_{2}-\mathrm{GlcNAc}$, and $(\mathrm{GlcN})_{2}$, respectively. The mass spectra confirmed the structures of the oligosaccharides obtained from the chitosanase digestion of Rhizopus cells.

The structure and function of CsnN174 have been intensively studied. $^{22,23}$ Splitting specificity of the enzyme was determined using the soluble substrate, partially $\mathrm{N}$-acetylated chitosan, and the enzyme was shown to hydrolyze the $\beta$-1,4-glycosidic linkage of the two sequences, GlcNAc-GlcN and GlcN-GlcN. Thus, the reducing-end residue of the oligosaccharides produced by this enzyme is GlcNAc or GlcN, while the nonreducing-end residue is exclusively GlcN. ${ }^{24}$ The enzymatic digestion of the Rhizopus cells produced the oligosaccharides GlcN-GlcNAc, (GlcN) $)_{2}-\mathrm{GlcNAc}$, and $(\mathrm{GlcN})_{2}$, indicating that the enzyme acts toward Rhizopus cells with the same splitting specificity as that toward the soluble substrate. It is likely that the chitosan polysaccharide chain in Rhizopus cells is sufficiently flexible such that the chitosanase directly interacts with the cell wall polysaccharide in a similar manner to that with the soluble substrate. The yields of $21 \mathrm{mg}(1.1 \%), 8 \mathrm{mg}$ (0.4\%), and $25 \mathrm{mg}$ (1.3\%) for the individual products, respectively, from $2 \mathrm{~g}$ of the intact cells appear to be very low. However, in 

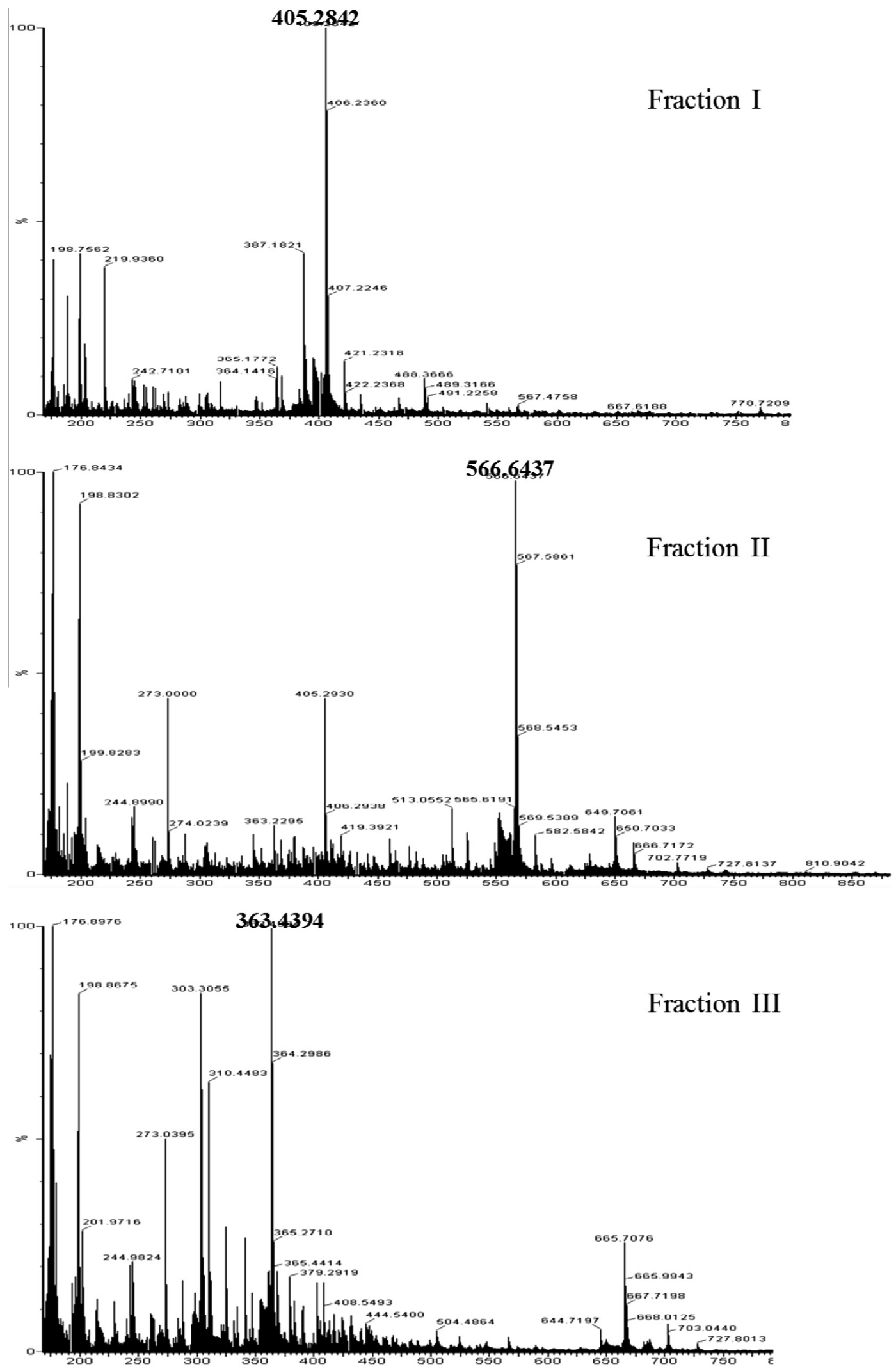

Figure 4. MALDI-TOF-MS of fractions I, II, and III. Spectra were recorded with a MALDI micro MX (Waters) in the positive ion reflection mode. Individual spectra showed three peaks at $\mathrm{m} / \mathrm{z}$ values of $405.2842,566.6437$, and 363.4394 , corresponding to the $\mathrm{m} / \mathrm{z}$ values of the sodium adduct ions of GlcN-GlcNAc, (GlcN) ${ }_{2}-\mathrm{GlcNAc}$, and $(\mathrm{GlcN})_{2}$, respectively.

the purification steps including charcoal column fractionation and cation exchange chromatography (Fig. 2), a number of the other oligosaccharide products, which were not structurally characterized, were removed. By means of other purification strategies, 
useful oligosaccharide products might be found in the products obtained from the same digestion system.

\subsection{Conclusion}

Intact $R$. oligosporus cells were directly hydrolyzed by chitinolytic enzymes. Among the enzymes tested, CsnN174 was found to act most efficiently toward the intact cells, producing GlcN-Glc$\mathrm{NAc},(\mathrm{GlcN})_{2}-\mathrm{GlcNAc}$, and $(\mathrm{GlcN})_{2}$. Since the chitosanase digestion of intact Rhizopus cells does not produce any environmental pollution, this strategy is excellent for the conversion of fungal biomass.

\section{Experimental}

\subsection{Materials}

Rhizopus oligosporus NRRL2710, of which the chitin/chitosan content was determined to be $32 \%$ (Yamashita et al., unpublished), was cultivated in a medium containing $5 \%$ dextrin, $1 \%$ yeast extract, and $0.5 \%$ ammonium sulfate ( $\mathrm{pH} \mathrm{5.5)}$ at $30{ }^{\circ} \mathrm{C}$ for 4 days. Cells were harvested, centrifuged, and washed with distilled water three times. After lyophilization, we obtained $7.3 \mathrm{~g}$ of the cells from one liter culture. A chitosanase from Streptomyces sp. N174 (CsnN174) was produced by the expression system using Streptomyces lividans TK-24, ${ }^{25}$ and gave a single band on SDS-PAGE. A thermophilic chitinase from Pyrococcus furiosus (PfChit) was kindly donated from Dr. Kazuhiko Ishikawa, Advanced Industrial Science and Technology (AIST), Japan, ${ }^{26}$ and also gave a single band on SDS-PAGE. The chitinase preparation obtained from the culture supernatant of Trichoderma viride (TvChit) was the product of Kyowa Chemical Co. We found that the TvChit preparation contains some impurities on SDS-PAGE and includes $\beta$-1,4-glucanase activity. Since the glucanase activity included in the TvChit preparation was less than $1 \%$ of the chitinase activity as judged from the degradation rates of the corresponding hexamer substrates, the contamination could be disregarded with respect to the experiments conducted in this paper. One unit of activity was defined as the amount of enzyme releasing $1 \mu \mathrm{mol}$ of the corresponding monomer per min at $37^{\circ} \mathrm{C}$.

\subsection{Enzymatic digestion of Rhizopus cells}

Three enzymes, CsnN174, PfChit, and TvChit, were tested for their ability to digest the intact cells. Dried Rhizopus cells (2 g) were suspended in $60 \mathrm{ml}$ of sodium acetate buffer at pH 5.0. At this $\mathrm{pH}$, the amino groups of chitosan polysaccharide are protonated and positively charged. Since the state of ionization of the cell wall appears to affect the accessibility of enzymes, the $\mathrm{pH}$ value was fixed in all enzymatic digestions. Individual enzymes (50 units) and $0.5 \mathrm{ml}$ of $2 \% \mathrm{NaN}_{3}$ were added to the cell wall suspension, and the reaction mixture was incubated for $24 \mathrm{~h}$ at $40{ }^{\circ} \mathrm{C}$. For the thermophilic enzyme, PfChit, the reaction was also conducted at $70{ }^{\circ} \mathrm{C}$, while the other reaction conditions were fixed. The enzymatic reaction was terminated by incubation in boiling water for $5 \mathrm{~min}$. After centrifugation of the reaction mixture, the precipitate was washed with distilled water three times, lyophilized, and weighed to calculate the solubilization percentage. Using the dried Rhizopus cells from an identical batch, each enzymatic digestion was repeated three times under the identical conditions.

\subsection{Solid state CP/MAS ${ }^{13} \mathrm{C}$ NMR spectroscopy}

Rhizopus dried cells, the insoluble fraction remaining after enzymatic digestion, and other reference compounds including chitin and chitosan were packed into a sample rotor (zirconium dioxide, $7 \mathrm{~mm}$ ). The solid state ${ }^{13} \mathrm{C}$ NMR experiments were performed on a
Bruker DSX-400WT spectrometer operating at a ${ }^{1} \mathrm{H}$ frequency of $400 \mathrm{MHz}$ using the combined techniques of proton dipolar decoupling (DD), magic angle spinning (MAS), and crosspolarization (CP). The contact time was $2 \mathrm{~ms}$, sweep width $35,211 \mathrm{~Hz}$, and recycle delay 5 s. Typically, 764 scans were acquired for each spectrum. Chemical shifts were externally referred by setting the carbonyl resonance of glycine to $176.03 \mathrm{ppm}$. The spinning speed was set to $5000 \mathrm{~Hz}$ for all samples.

\subsection{Purification of the products obtained from the chitosanase digestion of Rhizopus dried cells}

After digestion with CsnN174, the supernatant was applied to a column of charcoal $(3.5 \times 10 \mathrm{~cm})$, and the salts and unadsorbed fractions were removed by eluting with distilled water. The adsorbed oligosaccharides were recovered by eluting with $60 \%$ ethanol and evaporated under reduced pressure. Dried oligosaccharides were dissolved in $0.01 \mathrm{M}$ sodium acetate buffer, $\mathrm{pH} 5.0$ (buffer A), and put on a column of CM-Sephadex C-25 $(1.0 \times 75 \mathrm{~cm})$ previously equilibrated with buffer A. After the elution with buffer A, oligosaccharides adsorbed to CM-Sephadex resin were eluted with a linear gradient of $\mathrm{NaCl}$ from 0 to $1.0 \mathrm{M}$ in buffer $\mathrm{A}$. The reducing sugars were determined for individual tubes according to the modified Schales' method, ${ }^{27}$ and the fractions containing reducing sugars were pooled, evaporated under reduced pressure, and then applied to a gel-filtration column of Cellulofine $\mathrm{Gcl} 25-\mathrm{m}$ $(2.0 \times 180 \mathrm{~cm})$ using $0.05 \mathrm{M} \mathrm{NaCl}$ as an eluent. The purified oligosaccharide fractions were pooled, dialyzed against distilled water using an electric dialyzer, Micro Acilyzer G1 (AsahiKasei Kogyo), and then lyophilized. The lyophilized oligosaccharide products were used for structural characterization.

\subsection{Solution NMR spectroscopy}

Several milligrams of the purified oligosaccharide product were lyophilized three times from ${ }^{2} \mathrm{H}_{2} \mathrm{O}$, and then dissolved in $0.5 \mathrm{ml}$ of ${ }^{2} \mathrm{H}_{2} \mathrm{O}$. The $\mathrm{pH}$ value of each sample was determined by a direct meter reading without a correction for the isotope effect, and the sample was adjusted to approximately $\mathrm{pH} 4.0$ by the addition of concentrated ${ }^{2} \mathrm{HCl}$ or $\mathrm{NaO}^{2} \mathrm{H} .{ }^{1} \mathrm{H}$ and ${ }^{13} \mathrm{C}$ NMR spectra were obtained using a $5 \mathrm{~mm}$ probe on a Bruker AV400 N instrument.

\subsection{Mass spectrometry}

The oligosaccharide products were also analyzed by MALDITOF-MS. A portion of the oligosaccharide solution was mixed with an equal volume of 2,5-dihydroxy benzoic acid (2,5-DHB) and placed onto a plate in a MALDI micro MX (Waters).

\section{Acknowledgments}

This work was supported by 'Strategic Project to Support the Formation of Research Bases at Private Universities: Matching Fund Subsidy from MEXT (Ministry of Education, Culture, Sports, Science and Technology), 2011-2015 (S1101035). We are grateful to Dr. Kazuhiko Ishikawa, AIST, Japan, for kindly providing us the thermophilic chitinase (PfChit) preparation.

\section{References}

1. Muzzarelli, R. A. A. In Chitin and Chitinases; EXS, 1999; 87, pp. 1-6.

2. Hayes, M.; Carney, B.; Slater, J.; Bruck, W. Biotechnol. J. 2008, 3, 871-877.

3. Eijsink, V.; Hoell, I.; Vaaje-Kolstade, G. Biotechnol. Genet. Eng. Rev. 2010, 27, $331-366$.

4. Wang, Z.; Zheng, L.; Yang, S.; Niu, R.; Chu, E.; Lin, X. Biochem. Biophys. Res. Commun. 2007, 357, 26-31. 
5. Snaar-Jagalska, B. E.; Krens, S. F.; Robina, I.; Wang, L. X.; Spaink, H. P. Glycobiology 2003, 13, 725-732.

6. Semino, C. E.; Allende, M. L. Int. J. Dev. Biol. 2000, 44, 183-193.

7. Ngoa, D. N.; Kimb, M. M.; Kim, S. K. Carbohydr. Polymer. 2008, 74, 228-234.

8. Kaku, H.; Nishizawa, Y.; Ishii-Minami, N.; Akimoto-Tomiyama, C.; Dohmae, N. Takio, K.; Minami, E.; Shibuya, N. Proc. Natl. Acad. Sci. U.S.A. 2006, 103, 11086 11191.

9. Miya, A.; Albert, P.; Shinya, T.; Desaki, Y.; Ichimura, K.; Shirasu, K.; Narusaka, Y.; Kawakami, N.; Kaku, H.; Shibuya, N. Proc. Natl. Acad. Sci. U.S.A. 2007, 104 19613-19618.

10. Baker, L. G.; Specht, C. A.; Donlin, M. J.; Lodge, J. K. Eukaryot. Cell 2007, 6, 855 867.

11. Fukamizo, T.; Ohkawa, T.; Sonoda, K.; Toyoda, H.; Nishiguchi, T.; Ouchi, S.; Goto, S. Biosci., Biotechnol., Biochem. 1992, 56, 1632-1636.

12. Fukamizo, T.; Honda, Y.; Toyoda, H.; Ouchi, S.; Goto, S. Biosci., Biotechnol. Biochem. 1996, 60, 1705-1708.

13. Tan, S. C.; Tan, T. K.; Wong, S. M.; Khor, E. Carbohydr. Polymer. 1996, 30, 239242 .

14. Sitanggang, A. B.; Sophia, L.; Wu, H. S. Int. Food Res. J. 2012, 19, 393-404.

15. Hsieh, J. W.; Wu, H. S.; Wei, Y. H. Biotechnol. Prog. 2007, 23, 1009-1016.
16. Zamora, R. G.; Venum, T. L. J. Nutrit. 1979, 109, 1333-1339.

17. van Aalten, D. M.; Komander, D.; Synstad, B.; Gåseidnes, S.; Peter, M. G.; Eijsink, V. G. Proc. Natl. Acad. Sci. U.S.A. 2001, 98, 8979-8984.

18. Heux, L.; Brugnerotto, J.; Desbrieres, J.; Versali, M.-F.; Rinaudo, M. Biomacromolecules 2000, 1, 746-751.

19. Fukamizo, T.; Kramer, K. J.; Mueller, D. D.; Schaefer, J.; Garbow, J.; Jacob, G. S. Arch. Biochem. Biophys. 1986, 249, 15-26.

20. Tsukada, S.; Inoue, Y. Carbohydr. Res. 1981, 88, 19-38.

21. Fukamizo, T.; Ohtakara, A.; Mitsutomi, M.; Goto, S. Agric. Biol. Chem. 1991, 55, 2653-2655.

22. Marcotte, E. M.; Monzingo, A. F.; Ernst, S. R.; Brzezinski, R.; Robertus, J. D. Nat. Struct. Biol. 1996, 3, 155-162.

23. Fukamizo, T.; Brzezinski, R. Biochem. Cell Biol. 1997, 75, 687-696.

24. Fukamizo, T.; Honda, Y.; Goto, S.; Boucher, I.; Brzezinski, R. Biochem. J. 1995, 311, 377-383.

25. Boucher, I.; Fukamizo, T.; Honda, Y.; Willick, G. E.; Neugebauer, W. A.; Brzezinski, R. J. Biol. Chem. 1995, 270, 31077-31082.

26. Oku, T.; Ishikawa, K. Biosci., Biotechnol., Biochem. 2006, 70, 1696-1701.

27. Imoto, T.; Yagishita, K. Agric. Biol. Chem. 1971, 35, 1154-1156. 